\title{
Remediation of Diesel Contaminated Soil by Tween-20 Foam Stabilized by Silica Nanoparticles
}

\author{
R. Arun Karthick, and Pradipta Chattopadhyay
}

\begin{abstract}
Diesel oil spills into soil from petroleum storage areas, pipelines are a major environmental hazard. There is thus an increasing demand for new, efficient agents for remediation of diesel contaminated soil. The aim of this study therefore was to analyze the efficiency of application of nanoparticle stabilized nonionic surfactant foams for remediation of diesel contaminated soil. Stable foams were produced from dispersions of hydrophilic, hydrophobic silica nanoparticles with nonionic surfactant Tween-20. The foam generated was then transferred to a column containing the contaminated soil. The maximum diesel oil removal efficiency obtained by applying Tween-20 foam stabilized with $0.5 \mathrm{wt} \%$ hydrophobic silica nanoparticle was $78 \%$ - much higher than that obtained for Tween-20 foam stabilized with $0.5 \mathrm{wt} \%$ hydrophilic silica nanoparticles. The Tween-20 surfactant solution alone showed only $42 \%$ maximum oil removal efficiency.
\end{abstract}

Index Terms-Diesel, nonionic surfactants, silica nanoparticles, soil remediation, stable foams.

\section{INTRODUCTION}

Foam consists of gas phase dispersed in a continuous phase of liquid. The foamability and foam stability are crucial factors for the application of stable aqueous foam in removal of contaminants from soil [1]. It is a big challenge to apply suitable method and use efficient agents to treat contaminated soil [2], [3]. Diesel oil serves as major energy source in many countries. Fertile soil is prone to contamination with diesel seeping through pipelines during transport, leading to undesirable change in the subsurface of soil. This also leads to groundwater contamination. Diesel oil contamination was always a threat to environment thus causing a demand for robust contaminated soil remediation strategies with new, efficient agents [4]. It is thus very important to select a proper remediating agent that would completely solubilize the contaminants from soil. Surfactant remediation was earlier the primary technique to clear up the oil spills in land. Other methods such as using biological microbes to degrade diesel have also been reported [5]. The surfactants in water-soil heterogeneous system bring about removal of contaminant from soil by adsorbing on to the surface of soil. The amphiphilic nature of surfactant helped in solubilization of non-polar hydrocarbon contaminants on the soil surface. It

\footnotetext{
Manuscript received November 15, 2016; revised May 6, 2017. This work was supported by the Department of Science and Technology (DST), India under Ref. no. SB/FTP/ETA-208/2012.

The authors are with the Department of Chemical Engineering, BITS Pilani, Pilani 333031, Rajasthan, India (e-mail: arunkarthick90@ gmail.com, pradipta@pilani.bits-pilani.ac.in).
}

has been possible to achieve satisfactory diesel removal efficiency by using nonionic surfactants like Tween-80 [6]-[9].

Aqueous foams have been identified as a better and effective tool to improve the removal of non-aqueous phase liquids (NAPLs) from contaminated soil. The foams occupy larger space and typically require less surfactant solution. This distinguishing behavior between surfactant solution and foam plus the higher cost of surfactants have led to foam being a better soil remediating agent. It was established that use of aqueous foam in contaminated soil remediation overcomes various problems associated with application of surfactant solution [10]. On comparing the various literature available, it was found that the application of nanoparticle stabilized nonionic surfactant foams for remediation of diesel contaminated oil have been investigated very rarely and not in proper depth. Thus the present work aims to analyze the efficiency of remediation of diesel contaminated soil by application of nonionic surfactant Tween-20 foams, stabilized with hydrophilic and hydrophobic silica nanoparticles.

\section{MATERIALS AND METHODS}

\section{A. Materials}

Ultra-pure water prepared with Elix Millipore system was used throughout the study. The nonionic surfactant Tween-20 used for foam stabilization study was supplied by Himedia (India). Hydrophobic $\mathrm{SiO}_{2}$ nanoparticle of average particle size of $55 \mathrm{~nm}$ and with specific BET surface area of 195-245 $\mathrm{m}^{2} \mathrm{~g}^{-1}$ and density of $2 \mathrm{gcm}^{-3}$ was supplied by Evonik Canada Inc. Hydrophilic $\mathrm{SiO} 2$ nanoparticles (NanoLabs) used in the study had particle size in the range $50-80 \mathrm{~nm}$, surface area of $630 \mathrm{~m}^{2} \mathrm{~g}^{-1}$ and a density of $2.5 \mathrm{gcm}^{-3}$. Tetrahydrofuran (THF) obtained from Spectrochem (India) was used as solvent to pre-wet the nanoparticles. All the glasswares were cleaned and dried with 70 vol\% ethanol solution to prevent any contamination prior to experiments. Soil samples used in the study were collected locally and it was artificially contaminated with commercial diesel oil purchased from local petrol filling station.

\section{B. Experimental Procedures}

The silica nanoparticle and surfactant Tween-20 dispersion was prepared. The hydrophobic $\mathrm{SiO}_{2}$ nanoparticles formed clumps in water. In order to prevent this, nanoparticles were initially wetted with $1 \mathrm{~mL}$ of THF and dispersed in water. The dispersion was then sonicated using ultrasonic probe sonicator (Johnson Plastosonic, Mumbai, India) at $20 \mathrm{kHz}$ for $30 \mathrm{~min} \mathrm{[11],} \mathrm{[12].} \mathrm{Tween-20} \mathrm{was}$ dissolved in the prepared dispersion and used for further 
studies. Concentrations (vol\%) of Tween-20 tested in the study include $0.02,0.04,0.06,0.08$ and $0.1 \%$.

The foam properties of the prepared dispersion were analyzed using Dynamic Foam Analyzer DFA 100 (Kruss $\mathrm{GmbH}$, Germany). The principle behind operation of DFA 100 lies in generation of foam by passing air through the sintered glass filter having pore size of $40-100 \mu \mathrm{m}$ into the dispersion placed in a cylindrical glass column of length 250 $\mathrm{mm}$ and inside diameter of $40 \mathrm{~mm}$. The air was passed at a flow rate of at $0.3 \mathrm{~L} / \mathrm{min}$ for $12 \mathrm{~s}$ at the start of each run. This air flow rate and injection time was selected as it was the default setting for the Foam Analysis Software version 1.4.2.3 supplied by Kruss $\mathrm{GmbH}$, Germany. For all the foaming measurements, $50 \mathrm{~mL}$ of sample was used with air injection time of $12 \mathrm{~s}$ and total run time was fixed to be $900 \mathrm{~s}$ arbitrarily [13]. The results attained using the Dynamic Foam Analyzer DFA 100 along with the Foam Analysis Software included foamability and foam stability. All the experiments were repeated thrice and arithmetic average was considered. All foaming runs were conducted at room temperature of 298 $\pm 2 \mathrm{~K}$.

Soil sample used in the study was collected from non-contaminated agricultural field and characterized. Initially the collected soil was washed with water and dried at $128^{\circ} \mathrm{C}$ for $24 \mathrm{~h}$ [14]. Soil was screened by sieving through mesh size 30 BSS (British Standard Specification) to remove any large particles such as debris of sand, stone and dry leaves [15]. The soil was placed in hot air oven at $128^{\circ} \mathrm{C}$ for $24 \mathrm{~h}$ to remove any microbial contamination. The type and texture of soil typically affects the remediation of soil to a greater extent. Hence the soil was characterized prior to the experiments [16]. The characteristics of the soil sample used in remediation study are given in Table I. The heat treated soil was contaminated with diesel oil at the rate of $200 \mu \mathrm{L}$ per gram of soil and sealed tightly for $24 \mathrm{~h}$ prior to experiment so as to ensure complete adsorption of diesel oil on to the soil [17].

The soil remediation study was carried out in a column of 3 $\mathrm{cm}$ diameter and $30 \mathrm{~cm}$ length. A fine steel mesh was positioned at the exit of the column to trap the contaminated soil and to collect the effluent. The $100 \mathrm{~g}$ of contaminated soil was packed in layer by layer and tapped using glass rod [18, 19]. The foam generated using DFA 100 at a flow rate of 0.3 $\mathrm{L} / \mathrm{min}$ was transferred to the soil column and allowed to penetrate into the contaminated soil. The drained liquid from the column was collected and separated using separating funnel [20]. The diesel oil removal efficiency obtained by applying silica nanoparticle and Tween-20 stabilized foam was compared with the application of pure surfactant Tween-20 solution. The oil removal efficiency by foam generated by only surfactant Tween-20 and foam stabilized by combination of Tween- 20 and $\mathrm{SiO}_{2}$ nanoparticles at 0.5 wt $\%$ were determined by:

$$
\%=V_{0} V_{R} \times 100
$$

where, $\Pi \%$ - Percentage of diesel oil removed from contaminated soil; $V_{0}$-Volume of diesel oil removed by surfactant foam and $V_{R^{-}}$Volume of diesel oil present initially in the soil sample [21].

\section{RESULTS AND DISCUSSION}

A. Effect of Silica Nanoparticles on Foam Stability and Foam Volumes
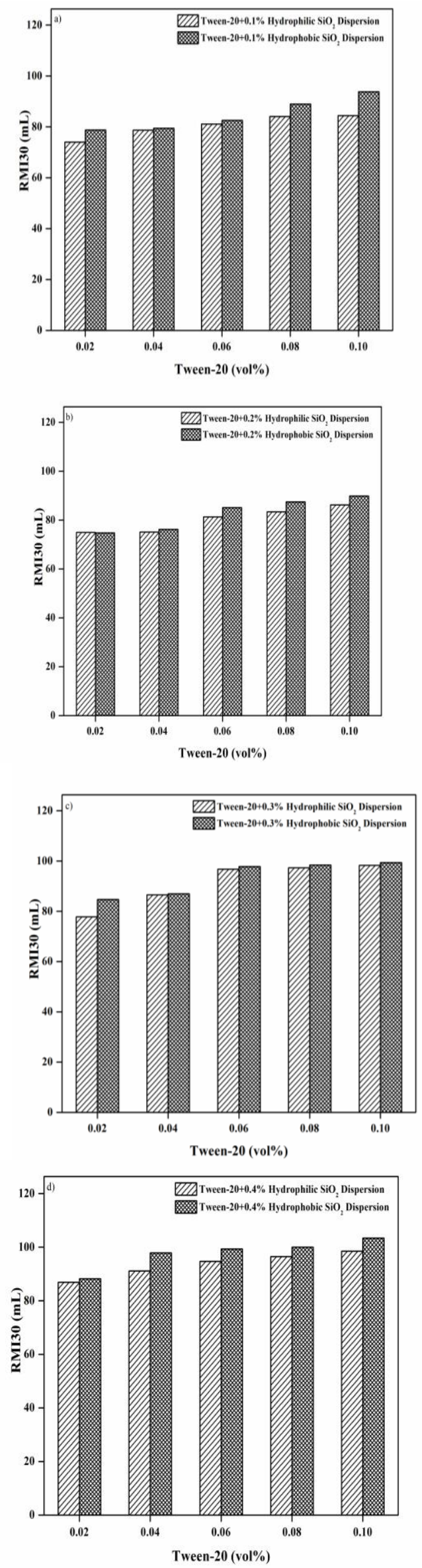


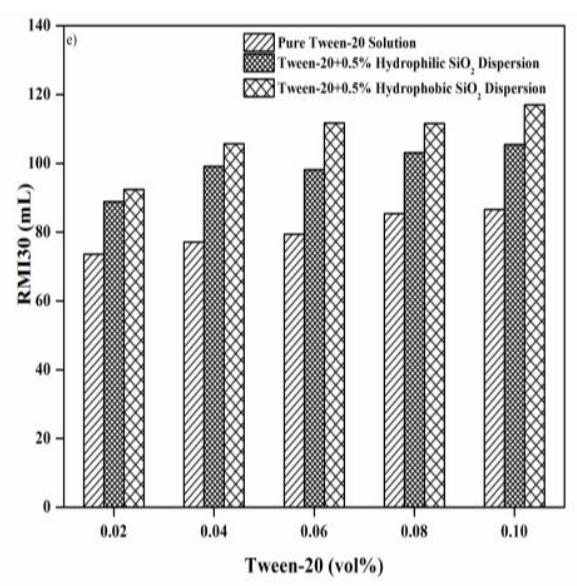

Fig. 1. Comparison of foam stability at various concentrations of hydrophilic and hydrophobic silica dispersions with Tween-20. a), b), c), d), e) represents the variations in RMI 30 values at $0.1,0.2,0.3,0.4,0.5 \mathrm{wt} \%$ of hydrophobic as well as hydrophilic silica nanoparticle concentrations respectively.

The foams were found to decay gradually at the end of air injection time of $12 \mathrm{~s}$ from the start of each run. Foam stability was measured in terms of Ross Miles Index (RMI 30) which described the volume of foam after $30 \mathrm{~s}$ collapse. The foam produced only with Tween-20 surfactant solution had very low RMI 30 value. As seen from Fig. 1, foam produced with $0.5 \mathrm{wt} \%$ hydrophobic $\mathrm{SiO}_{2}$ and 0.1 vol\% of Tween-20 had maximum RMI 30 of $117 \mathrm{~mL}$ whereas the foam produced with $0.5 \mathrm{wt} \%$ hydrophilic $\mathrm{SiO}_{2}$ and $0.1 \mathrm{vol} \%$ of Tween-20 had maximum RMI 30 of $105.5 \mathrm{~mL}$. Thus the foam stability is enhanced in the presence of hydrophobic $\mathrm{SiO}_{2}$ nanoparticle. The foam generated with surfactant Tween-20 solution alone and $0.5 \mathrm{wt} \%$ silica nanoparticle dispersion with Tween-20 surfactant was subsequently used for the contaminated soil remediation study. The reason for selecting the foam produced from $0.5 \mathrm{wt} \%$ silica nanoparticle dispersion in combination with Tween-20 surfactant was that the dispersion showed maximum foam stability.

TABLE I: PROPERTIES OF SOIL SAMPLE USED FOR REMEDIATION STUDY

\begin{tabular}{lc}
\hline $\begin{array}{c}\text { Properties of Soil } \\
\text { sample }\end{array}$ & Values \\
\hline Sand content $(\%)$ & 95.1 \\
Silt content $(\%)$ & 4 \\
$\mathrm{pH}$ & 8.31 \\
Density $\left(\mathrm{kg} \mathrm{m}^{-3}\right)$ & 1399 \\
\hline \hline
\end{tabular}

\section{B. Dynamic Foam Properties}

Fig. 2 illustrates the results for dynamic foam volume for dispersions of $0.5 \%$ hydrophobic and hydrophilic silica nanoparticles and $0.1 \%$ Tween-20. The dynamic change in volume of foam produced by passing air at a flow rate of 0.3 $\mathrm{L} / \mathrm{min}$ is plotted over a time period of $900 \mathrm{~s}$. Nanoparticles being a good foam stabilizer tend to form a stable foam volume over a time period [22].The initial rise in foam volume occurs because of air being passed. $0.5 \%$ hydrophobic silica nanoparticle produced higher foam volumes than the surfactant only solution and hydrophilic silica nanoparticle. Also it can be noted that both hydrophilic and hydrophobic nanoparticle produced stable foam volumes over the stated time period. The reason for this lies in the fact that the size of both types of silica nanoparticle used was around $50 \mathrm{~nm}$. It is known that the size of nanoparticles affects the generation of foam [23].

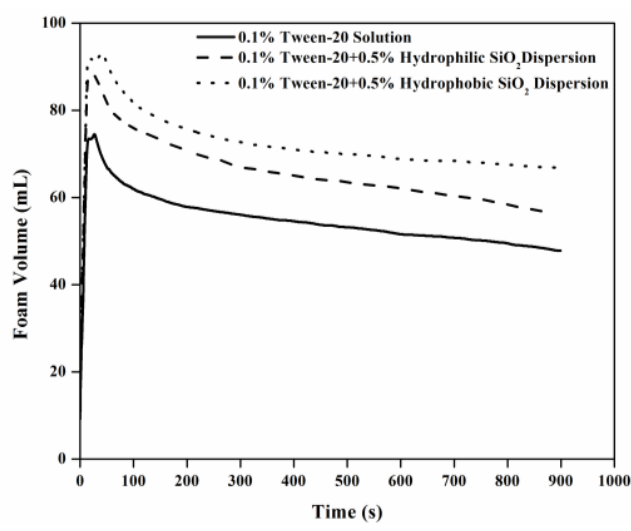

Fig. 2. Dynamic change in volume of foam generated using dispersion of 0.1 (vol\%) of Tween-20 and 0.5 (wt \%) of hydrophilic and hydrophobic silica nanoparticles.

The effect of silica nanoparticles on foam drainage was further investigated to describe the foam stability. Generally drainage is the phenomenon by which the liquid content in the foam drains by the effect of gravity. Not all the liquid from the foam drains due to capillary holdup until an equilibrium is reached. The liquid drainage pattern exhibited by dispersions of $0.5 \%$ hydrophilic and hydrophobic $\mathrm{SiO}_{2}$ nanoparticles with $0.1 \%$ of Tween-20 as well as only $0.1 \%$ Tween-20 solution is shown in Fig. 3. The volume of liquid all the cases initially increases and remains nearly constant [24].

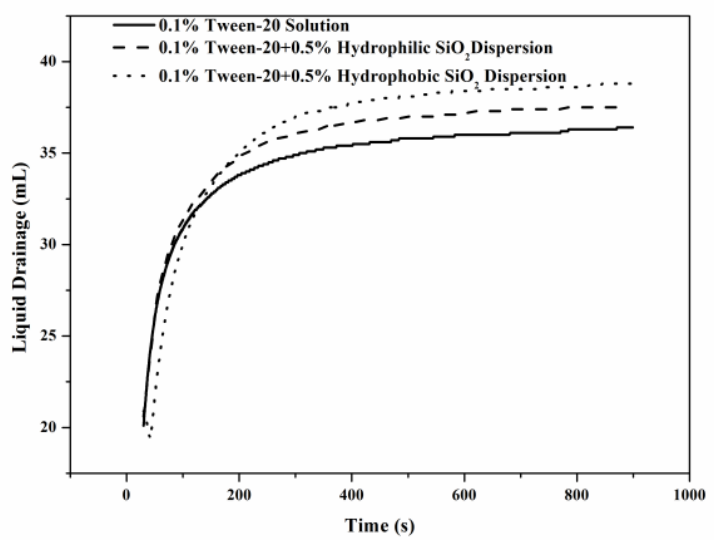

Fig. 3. Liquid Drainage using dispersion of 0.1 (vol\%) of Tween-20 and 0.5 (wt $\%$ ) of hydrophilic and hydrophobic $\mathrm{SiO}_{2}$ dispersion.

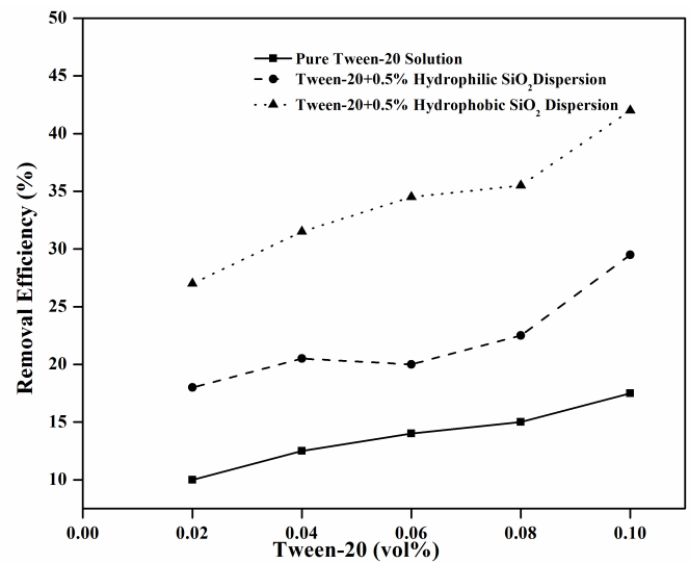

Fig. 4. Effects of application of surfactant Tween-20 solution and $0.5 \mathrm{wt} \%$ silica nanoparticle dispersions with Tween-20 on diesel oil removal efficiency from contaminated soil.

The amount of liquid drainage affects the foam stability which determines the removal of contaminants from soil 
surface. In the study conducted, the drainage of liquid from foam stabilized by $0.5 \%$ silica nanoparticles was found to be slower and higher diesel oil removal efficiency was noted. Though the mechanism by which silica hydrophobic particles affect drainage is unclear, the hydrophilic particles tend to adhere to the foam [25].

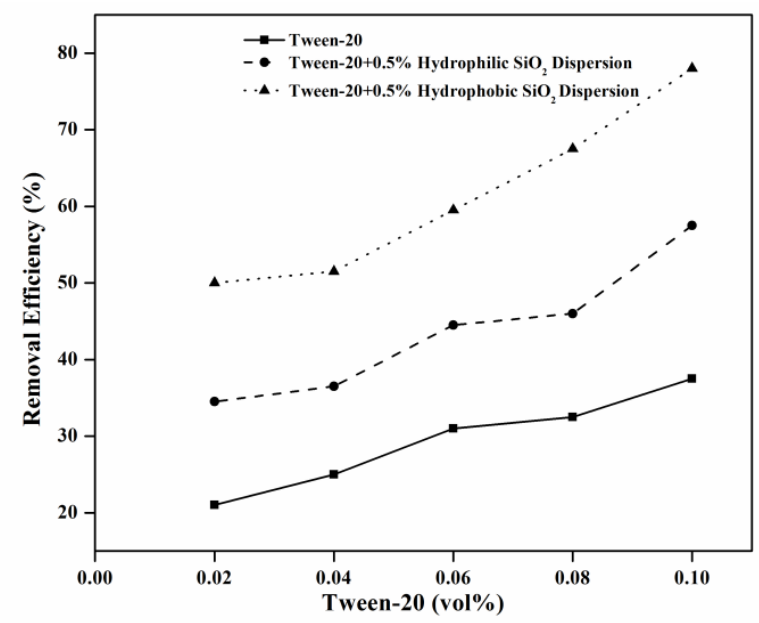

Fig. 5. Effects of application of surfactant foam stabilized by Tween-20 and $0.5 \mathrm{wt} \%$ silica nanoparticle dispersions with Tween-20 on diesel oil removal efficiency from contaminated soil.

\section{Soil Remediation Study}

With an objective to obtain higher oil removal efficiency from contaminated soil, the soil was treated with surfactant Tween-20 aqueous solution, dispersions of $0.5 \mathrm{wt} \% \mathrm{SiO}_{2}$ nanoparticles with Tween-20. The contaminated soil was subsequently treated with foams stabilized with Tween-20 solution as well as foams stabilized with dispersions of $0.5 \mathrm{wt} \%$ $\mathrm{SiO}_{2}$ nanoparticles and Tween-20. The oil removal efficiency of both surfactant solution and surfactant foam was shown in Fig. 4 and Fig. 5 respectively. The Tween-20 surfactant solution alone only showed $42 \%$ maximum oil removal efficiency from contaminated soil. It was also observed that the Tween-20 surfactant foam stabilized with hydrophobic $\mathrm{SiO}_{2}$ nanoparticle showed $78 \%$ maximum oil removal efficiency and the maximum oil removal efficiency obtained by Tween-20 surfactant foam stabilized with hydrophilic silica nanoparticles was only $57.5 \%$. The availability of silica nanoparticles to interact with contaminants was an important factor in achieving better soil remediation. The absence of nanoparticle in surfactant solution made it difficult to interact with soil and hence less oil removal efficiency was observed in that case. Also it was found that the hydrophobic silica nanoparticles tend to adsorb efficiently and thus made the foam much more stable. Higher the foam stability, higher was the oil removal efficiency from contaminated soil as mentioned in literature [26].

\section{CONCLUSIONS}

The applications of nanoparticles are vast in various fields in recent times. The process of stabilization of foam by using dispersions of nonionic surfactant (Tween-20) and different types of $\mathrm{SiO}_{2}$ nanoparticles and its subsequent application in removal of diesel oil from contaminated soil was demonstrated. The most stable foam was used in the soil remediation study. The hydrophobic silica nanoparticle dispersion along with different concentrations of Tween-20 produced better foamability and foam stability than hydrophilic silica nanoparticle dispersion at $0.5 \mathrm{wt} \%$ concentration. A significant improvement in oil removal efficiency was also seen for Tween-20 surfactant foam stabilized by silica nanoparticle than that for Tween-20 surfactant solution alone. Hence Tween-20 surfactant foam stabilized by silica nanoparticles are better capable for contaminated soil remediation compared to Tween-20 surfactant solution. Higher percentage of diesel oil removal from contaminated soil was attained by using Tween-20 foam stabilized by hydrophobic silica nanoparticle. The results obtained will be compared in future with that obtained for important biosurfactant foams, used for soil remediation.

\section{REFERENCES}

[1] K. Osei-Bonsu, N. Shokri, and P. Grassia, "Foam stability in the presence and absence of hydrocarbons: From bubble-to bulk-scale," Colloid Surface A, vol. 481, pp. 514-526, 2015.

[2] S. Zhu, M. Zhou, and S. Zhang, "Enhanced electrokinetic remediation of fluorine-contaminated soil by applying an ammonia continuous circulation system," Korean J. Chem. Eng., vol. 33, no. 2, pp. 547-552, February 2016.

[3] Y. C. Lee, M. H. Choi, J. I. Han, Y. L. Lim, and M. Lee, "A low-foaming and biodegradable surfactant as a soil-flushing agent for diesel-contaminated soil," Sep. Sci. Technol., vol. 48, no. 12, pp. 1872-1880, 2013.

[4] S. Gitipour, K. Narenjkar, E. S. Farvash, and H. AAsghari, "Soil flushing of cresols contaminated soil: application of nonionic and ionic surfactants under different $\mathrm{pH}$ and concentrations," J. Environ. Health Sci. eng., vol. 12, no. 129, pp. 1-6, 2014.

[5] N. N. Tshilumbu, E. Kharatyan, and I. Masalova, "Effect of nanoparticle hydrophobicity on stability of highly concentrated emulsions," J. Disper. Sci. Technol., vol. 35, no. 2, pp. 283-292, 2014.

[6] Y. Zhu, X. Pei, J. Jiang, Z. Cui, and B. P. Binks, "Responsive aqueous foams stabilized by silica nanoparticles hydrophobized in situ with a conventional surfactant," Langmuir, vol. 31, no. 47, pp. 12937-12943, December 2015.

[7] I. Lesov, S. Tcholakov, and N. Denkov, "Factors controlling the formation and stability of foams used as precursors of porous materials," J. Colloid Interface Sci.., vol. 426, pp. 9-21, 2014.

[8] X. Mao, R. Jiang, W. Xiao, and J. Yu, "Use of surfactants for the remediation of contaminated soils: A review," J. Hazard. Mater., vol. 285, pp. 419-435, March 2015.

[9] D. Huguenot, E. Mousset, E. D. Van Hullebusch, and M. A. Oturan, "Combination of surfactant enhanced soil washing and electro-Fenton process for the treatment of soils contaminated by petroleum hydrocarbons," J. Environ. Manage., vol. 153, pp. 40-47, April 2015.

[10] J. Maire, A. Coyer, N. F. Rouge, "Surfactant foam technology for in situ removal of heavy chlorinated compounds-DNAPLs," J. Hazard. Mater., vol. 299, pp. 630-638, 2015.

[11] T. Chen, L. Li, and G. Wang, "Selection of surfactant in remediation of DDT-contaminated soil by comparison of surfactant effectiveness," Environ. Sci. Pollut. Res., vol. 21, no. 2, pp. 1370-1379, January 2014

[12] A. J. Worthen, H. G. Bagaria, Y. Chen, S. L. Bryant, C. Huh, and K. P. Johnston, "Nanoparticle-stabilized carbon dioxide-in-water foams with fine texture," J. Colloid Interface Sci., vol. 391, pp. 142-151, February 2013.

[13] E. D. C. Estrada, H. Bertin, and O. Atteia, "Experimental Study of Foam Flow in Sand Columns: Surfactant Choice and Resistance Factor Measurement," Transp. Porous Med., vol. 108, no. 2, pp. 335-354, 2015.

[14] A. S. Ramamurthy, Z. Chen, X. Li, and M. Azmal, "Surfactant assisted removal of engine oil from synthetic soil," Environ. Prot. Eng., vol. 41, no. 2 , pp. 67-79, 2015.

[15] X. Wang, J. Chen, and C. Lv, "Evaluation of foam surfactant for foam-flushing technique in remediation of DDT-contaminated soil using data envelopment analysis method," Environ Sci Pollut Res., vol. 22, pp. 2994-3003, 2015

[16] P. P. Falciglia, M. G. Giustra, and F. G. A. Vagliasindi, "Soil texture affects adsorption capacity and removal efficiency of contaminants in ex situ remediation by thermal desorption of diesel-contaminated soils," Chem. Ecol., vol. 27, pp. 119-130, February 2011. 
[17] D. Feng and C. Aldrich, "Sonochemical treatment of simulated soil contaminated with diesel," Adv. Environ. Res., vol. 4, pp. 103-112, 2000.

[18] R. D. Villa, A. G. Trovó, and R. F. Nogueira, "Soil remediation using a coupled process: soil washing with surfactant followed by photo-Fenton oxidation," J. Hazard. Mater., vol. 174, no. 1-3, pp. 770-775, February 2010.

[19] D. H. Lee, R. D. Cody, D. J. Kim, and S. Choi, "Effect of soil texture on surfactant-based remediation of hydrophobic organic-contaminated soil," Environ. Int., vol. 27, no. 8, pp. 681-688, March 2002.

[20] M. M. Parnian and S. Ayatollahi, "Surfactant remediation of LNAPL contaminated soil; Effects of adding alkaline and foam producing substances," IJCHE, vol. 5, no. 2, pp. 34-44, 2008.

[21] H. J. B. Couto, G. Massarani, E. C. Biscaia Jr., and G. L. Sant Anna Jr. "Remediation of sandy soils using surfactant solutions and foams," $J$. Hazard. Mater., vol. 164, pp. 1325-1334, 2009.

[22] G. Bournival, and S. Ata, "Foaming and gas holdup of esterified nanoparticle dispersions in thepresence of sodium chloride," Colloid Surface A, vol. 480, pp. 245-252, 2015.

[23] F. AttarHamed, M. Zoveidavianpoor, and M. Jalilavi, "The incorporation of silica nanoparticle and alpha olefin sulphonate in aqueous $\mathrm{CO}_{2}$ foam: Investigation of foaming behavior and synergistic effect," Pet. Sci. Technol. vol. 32, pp. 2549-2558, 2014.

[24] S. Gauchet, M. Durand, and D. Langevin, "Foam drainage. Possible influence of a non-newtonian surface shear viscosity," J. Colloid Interface Sci., vol. 449, pp. 373-376, 2015.

[25] J. Wang, A. V. Nguyen, and S. Farrokhpay, "A critical review of the growth, drainage and collapse of foams," Adv. Colloid Interface Sci. vol. 228, pp. 55-70, 2016.
[26] R. C. G. Oliveira, J. F. Oliveira, and B. M. Moudgil, "The effect of hydrophobic fine particles on the foam flushing remediation process," Progr. Colloid Polym. Sci., vol. 128, pp. 293-297, December 2004.

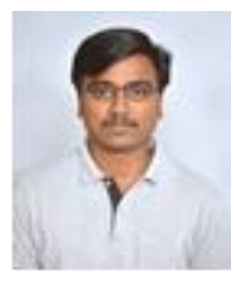

R. Arun Karthick completed B.Tech in biotechnology from Kalasalingam University, India and M. Tech, in pharmaceutical technology from SASTRA University, India. Currently, he is pursuing Ph.D. in Chemical Engineering Department, BITS Pilani, Pilani, India under the guidance of BITS Pilani Faculty Pradipta Chattopadhyay. His research interests include surfactants, foams, their characterization and applications.

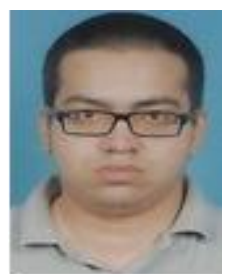

Pradipta Chattopadhyay did B.E. in chemical engineering discipline from Jadavpur University, India. He then completed M.S. from Texas A \& M University Kingsville, U.S.A. and Ph.D. from University of Tulsa, U.S.A. both in chemical engineering. He joined the Chemical Engineering Department, BITS Pilani, Pilani Campus, India in August, 2009 as an assistant professor. He has more than 7 years work experience as an assistant professor in Chemical Engineering Department, BITS Pilani, Pilani, India. His research interests include novel surfactant synthesis, aqueous foams, their characterization and applications. He has thirty five total publications in reputed journals, conference proceedings and book chapter. He is also a member of The Indian Institute of Chemical Engineers, India and Japan Oil Chemists' Society. 